\title{
TINJAUAN MANAJEMEN INVESTASI PADA PROYEK PLTM SITEBA IV KABUPATEN LUWU
}

\author{
Waluyo Sulistiono ${ }^{1}$ \\ ${ }^{1}$ Dosen FT Universitas Andi Djemma Palopo \\ waluyosulistiono@ymail.com
}

\begin{abstract}
Abstrak
Penelitian ini merupakan manajemen investasi PLTMH yang berlokasi di Desa Siteba Kecamatan Walenrang Utara kabupaten Luwu Propinsi Sulawesi Selatan. Peranan yang digunakan untuk analisis investasi adalah uji Pay Back Periode (PBP), Benefit Cost Ratio (B/C Ratio), Net Present Value (NPV), Profitability Index (PI), dan Internal Rate of Return (IRR). Sementara untuk uji tingkat pengembalian investasi digunakan uji ROI (Return of Invesment) dan MEC (Marginal Effecienci of Capital). Hasil penelitian menunjukan bahwa debit sungai makawa mampu membangkitkan daya sebesar $7500 \mathrm{~kW}$. Berdasarkan perhitungan diperoleh hasil Pay Back Periode (PBP) 4 tahun 8 bulan kurang dari waktu yang diisyaratkan selama 6 tahun. BEP (Break Even Poin) diperoleh titik impas dengan biaya Rp. 435.976.836.947 selama 6,56 Tahun. Benefit Ratio (BCR) sebesar 1,75 lebih besar dari 1, NPV On Project $=$ Rp. 77.315.882.558 > 0, IRR On Project yang diperoleh adalah $18 \%$ dan NPV On Equity $=R p .89 .421 .236 .401>0$,danIRR On Equity yang diperoleh adalah 25,26\%. Hasil perhitungan terhadap PBP, BCR, NPV, dan IRR, menunjukkan bahwa proyek ini layak untuk dilaksanakan. Selain itu dengan ROI sebesar $18 \%$ dan MEC sebesar $21 \%$ menunjukkan proyek PLTMH Siteba Energy IV layak untuk direalisasikan karena menguntungkan bagi investor.
\end{abstract}

Kata kunci : PBP, BCR, NPV, IRR, ROI, MEC.

\section{PENDAHULUAN}

Manajemen investasi merupakan manajemen profesional yang mengelola beragam sekuritas dengan tujuan untuk mencapai target investasi yang menguntungkan bagi investor. Pada perencanaan pembangunan PLTM diperlukan tinjauan manajemen investasi, dengan meninjau beberapa aspek, diantaranya adalah biaya yang dibutuhkan untuk menjalankan pembangunan PLTM, waktu pengembaliannya, dan jadwal kontrak pemanfaatannya. Keputusan investasi modal pada PLTM membutuhkan suatu analisis dan pertimbangan yang mendalam berdasar pada karakteristik proyek infrastruktur pembangunan PLTM yang sangat rentan terhadap resiko dan ketidakpastian, misalnya resiko finansial, resiko pasar, resiko sumberdaya manusia dan lain-lain. Oleh karena itu perlu dilakukan tinjauan manajemen investasi pada pembangunan PLTM sebelum dilakukan keputusan dana investasi dengan memperhatikan resiko yang ada.

Sehubungan dengan keterbatasan dana dalam pembangunan maka pemerintah memberikan peluang pada pihak swasta untuk menanamkan saham. Dari perspektif swasta, investasi akan menarik bila bersifat menguntungkan dan ada jaminan ketentraman berinvestasi dari pemerintah. Oleh sebab itu dilakukan peninjauan penelitian untuk mengetahui kelayakan manajemen investasi PLTM pada proyek PLTM Siteba IV, di Kabupaten Luwu, Desa Siteba oleh PT Siteba Energy.

Sebelum pengambilan keputusan pembangunan PLTM perlu dipertimbangkan ketersediaan tenaga dari debit sungai dan tinggi energi yang terisolasi dilokasi untuk menghasilkan tenaga potensial yang berguna, serta perbandingan jarak saluran aliran irigasi air (waterway) menuju terhadap bak penenang (headpond). Tenaga potensial teoritis suatu aliran yang mempunyai tinggi sebesar $\mathrm{H}(\mathrm{m})$ dan kapasitas debit sebesar Q $\left(\mathrm{m}^{3} /\right.$ detik) maka daya ( Pnet ) secara 
teoritis dihitung dengan persamaan (Adam Harvey Micro-hydro DesignManual 2000) :

dengan,

$$
\mathrm{P} \text { net }=\mathrm{g} \times \mathrm{Q} \times \mathrm{H} \times \eta
$$

$\mathrm{g}=$ Percepatan gravitasi $\left(9,8 \mathrm{~m} / \mathrm{s}^{2}\right)$

$\eta=$ efisiensi keseluruhan.

Setiap pembangunan sistem pembangkit selalu memperhitungkan biaya investasi, sehingga diperlukan data-data yang akurat tentang berbagai komponen Pembangkit Listrik Tenaga Minihidro (PLTM). Biaya investasi dapat dikelompokan atas beberapa komponen, untuk mempermudah perhitunganya di kelompokan menjadi dua komponen yaitu biaya modal dan biaya tahunan (Kodoatie, 2005). Biaya modal adalah semua pengeluaran yang dibutuhkan selama proyek berlangsung mulai dari pra-survey sampai proyek selesai di bangun. Biaya modal terdiri atas: (1) biaya pekerjaan survey; (2) biaya pekerjaan sipil; (3) biaya pekerjaan mekanikal dan elektrikal; (4) biaya pekerjaan jaringan distribusi; (5) biaya tidak langsung (biaya tak terduga). Prosentasenya dapat diestimasikan antara $5 \%$ sampai dengan $15 \%$ biaya tahunan. Biaya tahunan adalah biaya yang harus ditanggung oleh proyek selama umur proyek, yang termasuk biaya tahunan adalah: (1) bunga; (2) biaya penyusutan; (3) biaya operasi dan pemeliharaan.

Perusahaan Listrik Negara (PLN) merupakan produsen dan pembeli tunggal yang sampai saat ini membeli sekitar $80 \%$ tenaga listrik yang disediakan oleh perusahaan listrik swasta (Independent Power Producers). Kondisi kelistrikan semakin memburuk dengan adanya kenaikan harga bahan bakar minyak (BBM), sehingga memanfaatkan Daerah Aliran Sungai (DAS) menjadi energi baru terbarukan merupakan langkah yang baik untuk memenuhi kebutuhan masyarakat.

Hubungan nilai uang yang akan datang atau Future Value $(F V)$ terhadap nilai sekarang atau Present Value $(P V)$, nilai bunga/Interes (i) dan waktu (n) ditulis dengan rumus :

$$
\mathrm{FV}=\mathrm{PV}(1+\mathrm{i})^{\mathrm{n}}
$$

Cas flow proyek akan didiskonkan dengan suatu discont rate tertentu yaitu Weighted Average Cost of Capital (WACC) yang memperhitungkan adanya komposisi struktur pendanaan pada investasi modal. WACC merupakan rata-rata tertimbang dari cost of equity dan cost of debt yang dihitung setelah pajak. Dimana $r_{d}$ $=$ Cost of debt (biaya utang), $r_{e}=$ Cost of equity (biaya modal sendiri), $D=d e b t$ (pinjaman) dan $E=$ equity (modal) maka secara matematis ditulis :

$$
\mathrm{WACC}=(1-\mathrm{TAX}) \cdot \mathrm{r}_{\mathrm{d}} \frac{D}{D+E}+\mathrm{r}_{\mathrm{e}} \frac{E}{D+E}
$$

Break Even Point $(B E P)$ adalah titik pulang pokok dimana total revenue $=$ total cost $(\mathrm{TR}=\mathrm{TC})$. Titik impas memberikan petunjuk bahwa tingkat produksi telah menghasilkan pendapatan yang sama besarnya dengan biaya produksi yang dikeluarkan. Disamping dapat menyatakan hubungan antara volume produksi, harga satuan dan laba maka analisis titik impas memberikan informasi mengenai hubungan antara biaya tetap dan biaya variabel.

$$
\mathrm{BEP}=\frac{\text { Biaya tetap }}{1-\text { Biaya variabel pendapatan }}
$$

Internal Rate of Return (IRR) adalah suatu tingkat bunga (bukan bunga bank) yang jumlahnya sama dengan biaya investasi (project cost atau initial cost). Apabila WACC < IRR, maka investasi dikatakan layak. IRR dihitung menggunakan rumus : 


$$
\text { IRR }=i^{\prime}+\frac{\left(\text { PV dari i' }^{\prime}\right)}{\left(\text { NPV dari i } i^{\prime}+\text { NPV dari i" }\right)} \times\left(i^{\prime}{ }^{\prime}-i^{\prime}\right)
$$

Net Present Value (NPV) atau nilai bersih sekarang adalah selisih antara nilai sekarang netto selama umur proyek dengan nilai sekarang dari besarnya investasi. NPV $>0$, maka investasiproyek bisa dijalankan.NPV $<0$, maka investasiNPV $<0$, maka investasiproyek ditolak.

$$
\mathrm{NPV}=\sum_{t=1}^{n} \frac{\mathrm{CF}_{\mathrm{t}}}{(1+\mathrm{r}) \mathrm{t}^{\mathrm{t}}}
$$

Pay Back Period (PBP) atau periode pulang pokok adalah waktu yang dibutuhkan untuk mencapai titik impas. Apabila cash flow dari proyek investasi berbeda setiap tahun :

$$
\mathrm{PBP}=\mathrm{n}+\frac{\mathrm{a}-\mathrm{b}}{\mathrm{c}-\mathrm{b}} \times 1 \text { tahun }
$$

$\mathrm{PBP}<$ dari waktu maksimum yang diisyaratkan, proyek diterima.

PBP > dari waktu maksimum yang diisyaratkan, proyek ditolak.

Benefit Cost Ratio (BCR) adalah persentase pertumbuhan keuntungan selama setahun, yang dapat dicari berdasarkan keuntungan pada tahun tersebut.

$$
\mathrm{BCR}=\frac{\text { Benefit }(\operatorname{tahun} \mathrm{t})}{\text { Investasi }}
$$

Jika BCR $>1$ maka investasi diterima. Jika $\mathrm{BCR}<1$ maka investasi ditolak

Return of Investment (ROI) atau laba atas investasi adalah rasio uang yang diperoleh atau hilang pada suatu investasi, relatif terhadap jumlah uang yang diinvestasikan, dan dinyatakan dalam bentuk persentasi. ROI sering dinyatakan dalam satuan tahunan.

$$
\mathrm{ROI}=\frac{(\text { Total penjualan-investasi })}{\text { Investasi }} \times 100 \%
$$

Marginal Effecienci of Capital (MEC) adalah tingkat pengembalian yang diharapkan dari setiap tambahan barang modal,atau menyatakan besarnya keuntungan yang akan diperoleh dengan ditanamnya modal (investasi) terhadap pengembalian modal yang ditanamkan.

\section{METODOLOGI PENELITIAN}

Metode penelitian yang digunakan dalam penelitian ini adalah metode analitis dan deskriptif kuantitatif.

a) Metode Pengumpulan Data

Metode yang digunakan adalah mengumpulkan sejumlah data-data tertulis pada proyek pembangunan PLTM Siteba IV, sumber-sumber yang berhubungan dengan masalah yang diangkat, dan melalui studi pustaka dengan menggunakan literatur, buku, jurnal maupun internet.

b) Metode Analisis Data

Metode analisis data yang digunakan adalah dengan melakukan analisis tingkat kelayakan investasi dan analisis tingkat pengembalian investasi yaitu analisa kelayakan investasi berupa analisis dengan metode PBP, BCR, NPV, dan IRR. Selanjutnya, menganalisa pengembalian investasi berupa analisis dengan metode ROI, dan MEC.

\section{HASIL DAN PEMBAHASAN}

Pengukuran debit PLTM, seperti yang terlihat pada gambar 1 di bawah. Saluran air memiliki kecepatan aliran $1,2 \mathrm{~m} / \mathrm{s}$, lebar 4,8 m, tinggi 2,6 m. Sehingga diperoleh debit $\mathrm{Q}=(1,2 \times 4,8 \times 2,2)= \pm 12,5 \mathrm{~m}^{3} / \mathrm{s}$. 


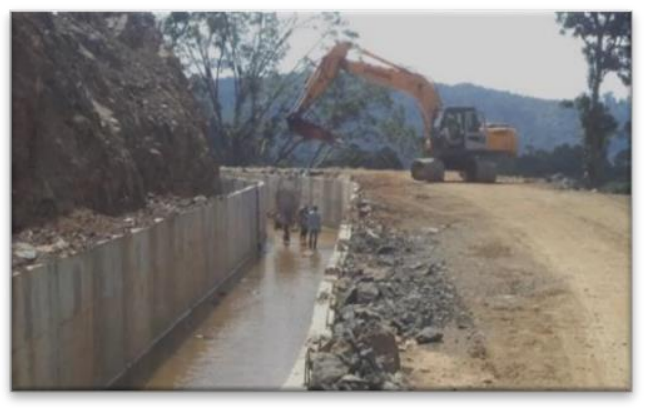

Gambar 1. Saluran air PLTM

Besarnya kapasitas daya tergantung pada debit air masuk dan beda tinggi, yang tersedia di lokasinya. Data di lokasi PLTM Siteba IVsesuai data-data hasil penelitian dengan faktor kapasitas $=80 \%$ sebagai berikut, debit (Q) desain $=$ $12,5 \mathrm{~m}^{3} /$ detik, tinggi jatuh $(\mathrm{H})$ bersih $=74.50$ meter, efisiensi Turbin $=0,82$, specific gravity air $=1\left(\right.$ ton $\left./ \mathrm{m}^{3}\right)$, percepatan gravitasi $=9,81\left(\mathrm{~m} / \mathrm{det}^{2}\right)$, efisiensi transmisi $(\eta$ gearbox) $=0,98$, efisiensi generator $(\eta \mathrm{g})=0,97$, daya output turbin adalah sebagai berikut:

$$
\begin{array}{ll}
P_{\text {output turbin }} & =\gamma \times g \times H \times Q \times \eta t(k W) \\
P_{\text {output turbin }} & =1 \times 9.81 \times 74.50 \times 12,5 \times 0.82 \\
& =7.591,7 \mathrm{~kW}=7,5 \mathrm{MW}
\end{array}
$$

Daya yang dihasilkan oleh PLTM Siteba IV adalah sebesar 7.500 Kilo-Watt $(\mathrm{kW})$ atau sama dengan 7.500.000 Watt, dengan asumsi bahwa setiap KK rata-rata menggunakan daya listrik 900 Watt per KK, maka daya sebesar ini bisa melayani sebanyak 8.333. KK.

Untuk meninjau daftar harga (hasil penjualan) daya listrik per tahun di ambil data-data yang akan digunakan sebagai berikut :
a) Kapasitas daya terpasang
b) Operasional daya 24 jam x 365 hari
c) Avaibiliti factor
$=7.500 \mathrm{~kW}$
d) Faktor kapasitas
$=8.760 \mathrm{jam}$
$=98 \%$
$=80 \%$
e) Tarif harga PLN per kW (Permen ESDM 031/2014)
$=\operatorname{Rp} 1.075$
f) Wilayah sulawesi selatan memilik faktor tarif
$=1,2$ per $\mathrm{kW}$

Dari hasil perhitungan biaya dari data-data diatas, sehingga jumlahnya diperoleh biaya total (total revenue) harga daya listrik per tahun mulai tahun 2015 sampai dengan tahun 2029 dengan biaya tiap-tiap tahun aliran cash sebesar $=7.500$ kW x 8.760 jam x 98\% x 80\% x Rp. 1.075 x 1,2 = Rp 66.502.080.000.

Dengan biaya penjualan per tahun, dilakukan analisa biaya pemanfaatan yang digunakan untuk mengetahui hubungan antara biaya, volume penjualan dan profitnya. Data-data operasi Pembangunan PLTM Siteba IV dan pemanfaatan dari tahun 2015 sampai 2029 diasumsikan sebagai berikut :
a) Operation \& Maintenance Cost
$=10 \%$
b) Other Expenses (CSR and Other)
$=1 \%$
c) Eskalasi (O\&M, Other Expenses)
$=5 \%$
d) Suku bunga
$=12 \%$ per tahun
e) Masa Pembangunan
$=4$ tahun
f) Masa Pengembalian Pinjaman
$=6$ tahun
g) Masa Kontrak Jual Beli Listrik
$=15$ tahun 
Maksud model ini adalah memperkenalkan adanya resiko dan ketidak pastian pada cash flow melalui analisis stokastik dimana parameter yang dihasilkan adalah berupa tingkat pengembalian dan koefisien variasi sebagai representasi dari resiko yang di kenal dengan metode dual risk-return.

WACC $=[\%$ modal $(\%$ bunga $x 1,4)]+[\%$ pinjaman $(\%$ bunga $(1-0,25))]$

$$
\begin{aligned}
& =[30 \%(12 \% \times 1,4)]+[70 \%(12 \%(1-0,25))] \\
& =11,34 \%
\end{aligned}
$$

Biaya variabel mempunyai hubungan erat dengan tingkat hasil produksi berupa daya keluar per hari. Data yang merupakan VC pertahun diasumsikan dalam tabel ini :

Tabel. 1. Variabel cost

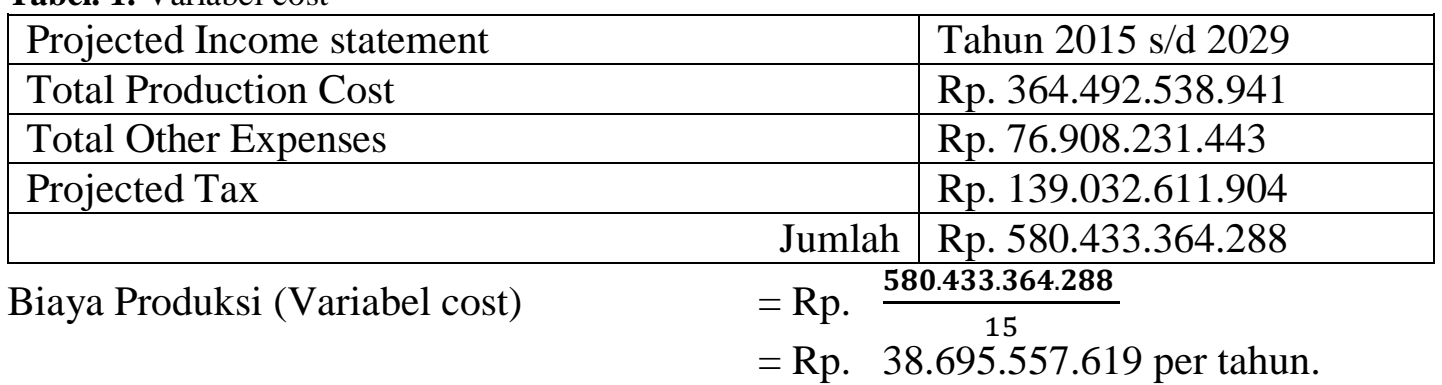

Fixed Cost (FC)diperoleh dengan persamaan $\mathrm{FC}=\mathrm{RAB}-\mathrm{VC}$
1. Biaya RAB
$=$ Rp. 220.990.602.738,
2. Biaya Variabel Cost
$=$ Rp. 38.695.557.619
$=$ Rp. 182.295.045.119. per tahun

Sehingga dalam pertahunnya diasumsikan biaya tetap rata-rata sama yaitu dengan Rp. 182.295.045.119 pertahun.

Pada pembangunan PLTM Siteba IV perusahaan mengeluarkan data berupa biaya Variabel Rp. 38.695.557.619. Harga daya listrik dijual ke PLN dengan daya $7500 \mathrm{~kW}$ per tahun sebesar Rp. 66.505.080.000. Perhitungan BEP seperti dibawah ini :

$$
\begin{aligned}
\mathrm{BEP} & =\frac{\text { Biaya tetap }}{\left(1-\frac{\text { Biaya Variabel }}{\text { Hasil Penjualan }}\right)}=\frac{\text { Rp. 182.295.045.119. }}{\left(1-\frac{\mathrm{Rp} .38 .695 .557 .619 .}{R p .66 .502 .080 .000}\right)} \\
& =\quad \mathrm{Rp} \text {. 435.976.836.947 }
\end{aligned}
$$

Perhitungan berdasarkan unit daya atau waktu

$$
\mathrm{BEP}=\left(\frac{(F C)}{\text { Harga Jual-VC }}\right)=\left(\frac{(182.295 .045 .119)}{66.502 .080 .00-38.695 .557 .619}\right)=6,56 \text { tahun }
$$

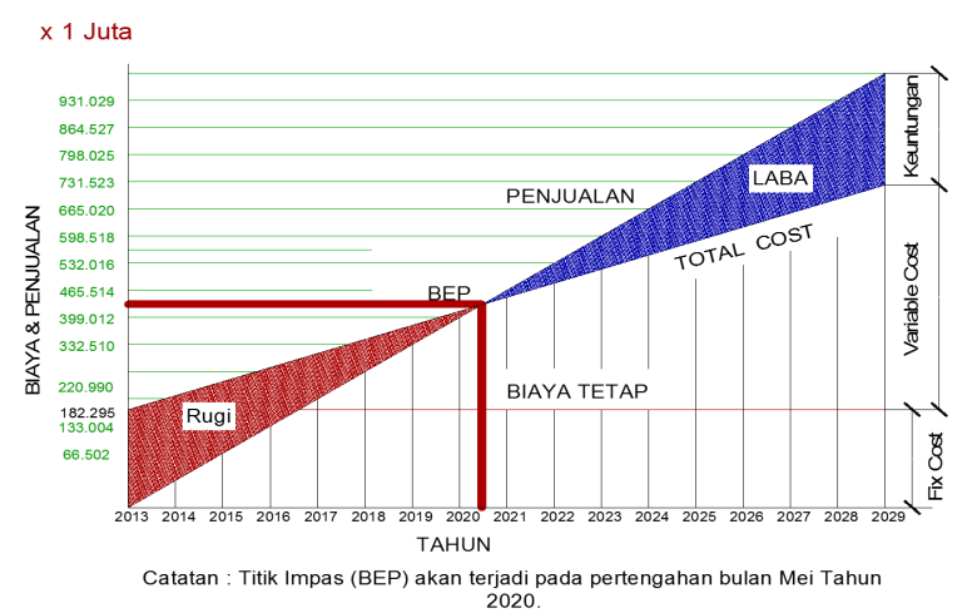

Gambar 2. Diagram BEP PLTM Siteba IV 
PBP adalah metode yang digunakan untuk mengukur waktu yang dibutuhkan agar investasi yang direncanakan dapat dikembalikan. Semakin pendek pay back period dari periode yang disyaratkan 6 tahun dari perusahaan (PBP $<6$ thn), maka investasi pada proyek tersebut dapat diterima.

$$
\begin{aligned}
\text { PBP } & =4+\left[\left\{\frac{[(30.398 .818 .787))}{(16.492 .138 .180+30.398 .818 .787)}\right\} x(5-4)\right] \\
& =4 \text { Tahun, 8 Bulan }
\end{aligned}
$$

Karena PBP $<6$ thn, maka proyek dapat diterima.

Analisa Net Present Value pada seluruh aliran cash di present value kan dengan reguired rate of return $(k)$ atau lebih tepatnya adalah WACC.

NPV On Project $=R p .77 .315 .882 .558$.

$$
\mathrm{NPV}=\sum_{t=0}^{n} \frac{A_{t}}{(1+K)_{t}}
$$

Analisa Benefit Cost Ratio (BCR) pada proyek pembangunan PLTM Siteba IV adalah sebagai berikut :

Jumlah Biaya (EAT + Interest + Depreciation \& Amortization) dalam 15 tahun adalah Rp. 386.733.554.791. Sedangkan biaya Modal adalah Rp. 220.990.602.738

$$
\mathrm{BCR}=\frac{\mathrm{NPV}(\text { WACC } ; \Sigma \text { pada Cash inflow } 2015 \mathrm{~s} / \mathrm{d} 2029)}{\mathrm{NPV}(\text { WACC } ; \Sigma \text { Cash Out }(2013-2014)}=\frac{386.733 .554 .791}{220.990602738}
$$

Dari hasil perhitungan diperoleh bahwa 1,75 > 1 sehingga layak untuk dijalankan.

Untuk menentukan nilai IRR dilakukan dengan cara trial and error (cobacoba) dengan mendapatkan nilai NPV (+) dan NPV (-).Jika modal $=$ Rp. 220.990.602.738dan waktu pengembalian 4 tahun 8 bulan dengan biaya rata-rata $\mathrm{Rp}$. 47.496.548.170 dan memilikisisa Rp. 16.492.138.180. Untuk mencari nilai $\ddot{X}=$ $\frac{220.990 .602 .738}{47.496 .548 .170}=4,65277$. Dengan asumsi nilai ini bisa kita lihatnilai ekonomis 10 tahun pada tabel nilai sekarang dari anuiti $R p .1 . P V=1 / r\left(1-(1+r)^{\wedge}-n\right)$ sehingga diperoleh nilai yang mendekati 4,65277 (lihat lampiran 4) sebagai berikut:

$$
\begin{aligned}
& \text { [ IRR }\left(\left\{\begin{array}{lll}
17 & \% & 4,65860 \\
\ddot{X} \% & 4,65277
\end{array}\right\} 0,00583\right) 0,15868 \text { ] } \\
& \mathrm{IRR}=18 \%+\frac{(0,00583)}{(0,00583+0,15868)} x(18-17)=18,0 \% \\
& \text { IRR On Project }=\text { Pada net cash flow dari thn } 2013 \text { s/d } 2029 \\
& =\operatorname{IRR}(\text { NCF } 2013 \text { s/d NCF 2029) }=18,0 \%(\text { Lampiran 4) }
\end{aligned}
$$

Berikut adalah perhitungan ROI :

Diketahui : Suku bunga $12 \%$ per tahun.

Aliran kas masuk = Rp. 66.502.080.000 x 15 thn

$$
=\text { Rp. 997.531.200.000 }
$$

Total investasi $\mathrm{RAB}=\mathrm{Rp} .220 .990 .602 .738$

$$
\mathrm{ROI}=\left[\frac{[(\text { Total penjualan } x \text { 15 })-\text { investasi })]}{\text { Investasi }} \times 100 \%\right] / 15 \text { Tahun }
$$

Diketahui : Bunga 12\% per tahun.

$$
\begin{aligned}
& \text { Aliran kas masuk = Rp. 66.502.080.000 x } 15 \text { thn } \\
& =\text { Rp. 997.531.200.000 } \\
& \text { Total investasi RAB = Rp.220.990.602.738 } \\
& \mathrm{ROI}=\left[\frac{(\mathbf{9 9 7 . 5 3 1 . 2 0 0 . 0 0 0 - 2 2 0 . 9 9 0 . 6 0 2 . 7 3 8 )}}{(\mathbf{2 2 0 . 9 9 0 . 6 0 2 . 7 3 8 )}} \times 100 \%\right] / 15 \text { thn }=23 \% \text { pertahun. } \\
& \mathrm{ROI}=23 \%-12 \%=11 \% \text { pertahun } \text {. }
\end{aligned}
$$


Return of Investment (ROI) yang disebut sebagai laba atas investasi yaitu rasio uang yang diperoleh pada suatu investasi, relatif terhadap jumlah uang yang diinvestasikan. Dari hasil perhitungan pada proyek pembangunan PLTM Siteba IV diperoleh ROI sebesar $11 \%$,pertahun. Hal ini berarti bahwa proyek pembangunan PLTM Siteba IV apabila dikerjakan oleh investor akan menguntungkan bagi investor sebesar $11 \%$ dari biaya modal tiap tahun.

Dari hasil perhitungan MEC pada proyek pembangunan PLTM Siteba IV diperoleh hasil perhitungan sebagai berikut :

Telah diketahui Jumlah Net Cash Flow dalam Cash In-Flow :

Jumlah aliran NCF on project tahun (2015 s/d 2029) = Rp. $\quad 685.006 .953 .317$

Modal

=Rp. 220.990.602.738

$$
\text { MEC }=\left\{\frac{685.006 .953 .317}{220.602 .738}\right\} \times 100 \%
$$$$
=21 \%
$$

MEC $=21 \%>$ bunga standar $12 \%$ per tahun.

Karena MEC menyatakan besarnya keuntungan yang akan diperoleh dengan ditanamnya modal. Apabila tingkat bunga yang berlaku di pasar uang sebesar $12 \%$ pertahun, sedangkan keuntungan yang diperoleh dari hasil sebesar $21 \%$, maka investasi tersebut masih menguntungkan yaitu $21 \%-12 \%=9 \%$ pertahun, atau ratarata keuntungan yang diperoleh oleh perusahaan adalah sebesar $9 \%$.

\section{PENUTUP}

\section{Kesimpulan}

Dari hasil penelitian ini dapat peroleh bahwa investasi, Pay Back Periode (PBP) diperoleh PBP proyek 4 tahun 8 bulan atau lebih singkat dari PBP waktu yang diisyaratkan yaitu 6 tahun, $\mathrm{BEP}=\mathrm{Rp} .435 .976 .836 .947$, Perhitungan berdasarkan unit daya atau waktu BEP $=6,56$ tahun. Benefit Ratio (BCR) diperoleh sebesar 1,75> 1, ini berarti bahwa proyek ini dikatakan layak untuk dikerjakan.NPV On Project $=$ Rp. 77.315.882.558. Dan hasil IRR On Project $=18 \%>$ WACC 11,34 \%, maka hal ini menunjukkan proyek ini layak. Hasil ROI sebesar 18\% dan MEC sebesar $21 \%$, yang menunjukkan proyek ini dapat dijalankan karena menguntungkan bagi investor. Hasil dari perhitungan tersebut di atas maka dapat disimpulkan bahwa proyek pembangunan PLTM Siteba IV layak untuk dijalankan dari aspek keuangan dan menguntungkan bagi PT. Siteba Energy.

Saran

Adapun saran dari hasil penelitian ini adalah Untuk investor agar memperhatikan hal-hal yang dapat memperlambat pelaksanaan proyek seperti bencana longsor dapat diminimalisir serta melakukan pendekatan pada masyarakat dan memahami keinginan masyarakat setempat sehingga dapat meminimalisir demonstrasi yang kemungkinan akan dilakukan oleh masyarakat setempat. Dan untuk pemerintah agar mempermudah bagi para investor dalam mengurus perizinan yang berkaitan penanaman modal dengan investasi dalam bidang pembangkit listrik tenaga minihidro (PLTM) dan juga agar memberi data yang akurat yang dibutuhkan oleh para investor.

\section{DAFTAR PUSTAKA}

Adam Harvey Micro-hydro Design Manual 2000.

Kodoatie, Robert J. ,2005, Analisis Ekonomi Teknik. Penerbit Andi Yogyakarta. Yogyakarta . 
Kuswadi, 2012, Analisis Keekonomian Proyek, Penerbit Andi, Yogyakarta. Penerbit CV ANDI OFFSET. Jl. Beo 38-40, Telp (0274) 561881, Fax. (0274) 588282 Yogyakarta.

Muhammad Idwenda Dachyar, 2012, Analisis Kelayakan Investasi dan Risiko Proyek Pembangunan PLTU Indramayu PT. PLN (Persero), Tesis, Fakultas Ekonomi, Universitas Indonesia, Jakarta.

Mulyadi, (2009) Activity Based Cost System; Sistem informasi biaya untuk engurangan biaya, UMPAMP YKPN, Yogyakarta.

Muniya Alteza, M.Si , 2010, Diktat Manajemen Investasi Jurusan Manajemen Fakultas Ilmu Sosial Dan Ekonomi Universitas Negeri Yogyakarta, Yogyakarta.

Murdifin Haming,Prof, SE, M.Si, Ph.D. Salim Basalamah, Prof. Dr. SE, M,Si. 2010 Studi Kleayakan Investasi Proyek \& Bisnis. Penerbit PT. Bumi Aksara. Jln Sawo Raya No 18. Jakarta 13220.

Paruntu. Svetlana, 2012, Analisis Cost Awareness dan Cost Monitoring untuk Efisiensi Biaya Pelayanan di Sub Departemen Radiologi Rumkital Dr. Mintohardjo (Studi kasus : Pelayanan Thoraks AP/PA Foto), Tesis, Universitas Indonesia, Jakarta. 